\title{
Heuristic Based Power Consumption Minimisation and Optimisation on Smartphones
}

\author{
G. B. Suresh ${ }^{1}$, V. Mathivanan ${ }^{2}$ \\ ${ }^{1}$ Research Scholar AMET University, Chennai \\ ${ }^{2}$ Professor, SRM University, Chennai
}

\section{Article Info \\ Article history: \\ Received Oct 22, 2017 \\ Revised Dec 27, 2017 \\ Accepted Jan 10, 2018 \\ Keywords: \\ Power Consumption \\ Minimisation \\ Power Optimisation \\ Smartphones}

\section{Corresponding Author:}

G. B. Suresh,

Research Scholar,

AMET University,

Chennai.

\begin{abstract}
In the direction of capable save the energy of battery life in Smartphone accurate with sensible influence form of Wi-Fi data communication in infrastructure mode. The network environment parameters like still time in a 3G system the network throughput and the convey pattern have been accepted all through measurement study the collective impact of an issue has not been systematical.
\end{abstract}

\section{INTRODUCTION}

Partition cellular phone tradition has grown in the recent years and has extended from only influence air force to other complicated services such as social network distraction and learning within malevolence of the critical capability of the modern smartphones their accessibility relies on the limited battery reality [1],[2]. Smartphone needs a collection of applications that use the hardware to provide such services to its user. To satisfy a user's needs, applications need to run semi-constantly in the background or utilise hardware components often.

The organisation applications power contains energy bugs that intensely affect the energy utilisation. As a result, the operation time reduces particularly which is a usability concern at present [3]. It seems that engineers are incapable of increasing the amount of energy created by the chemical reactions in relatively small size battery [4],[5]. This results in shrinking battery life as the development of battery technology is unable to keep up with the energy demand of applications.

\section{PROPOSED SYSTEM}

The essential scheme is toward approximation the power utilisation of the hardware mechanism with the help of the predefined situation technology. Appraise the planned power models during methodical observed experiment happening three mobile platforms and in the different network environment. Analyzed the impact of option explodes coverage threshold with the general granularity of the input going on the resultant power opinion accuracy. 


\section{ARCHITECTURE DIAGRAM}

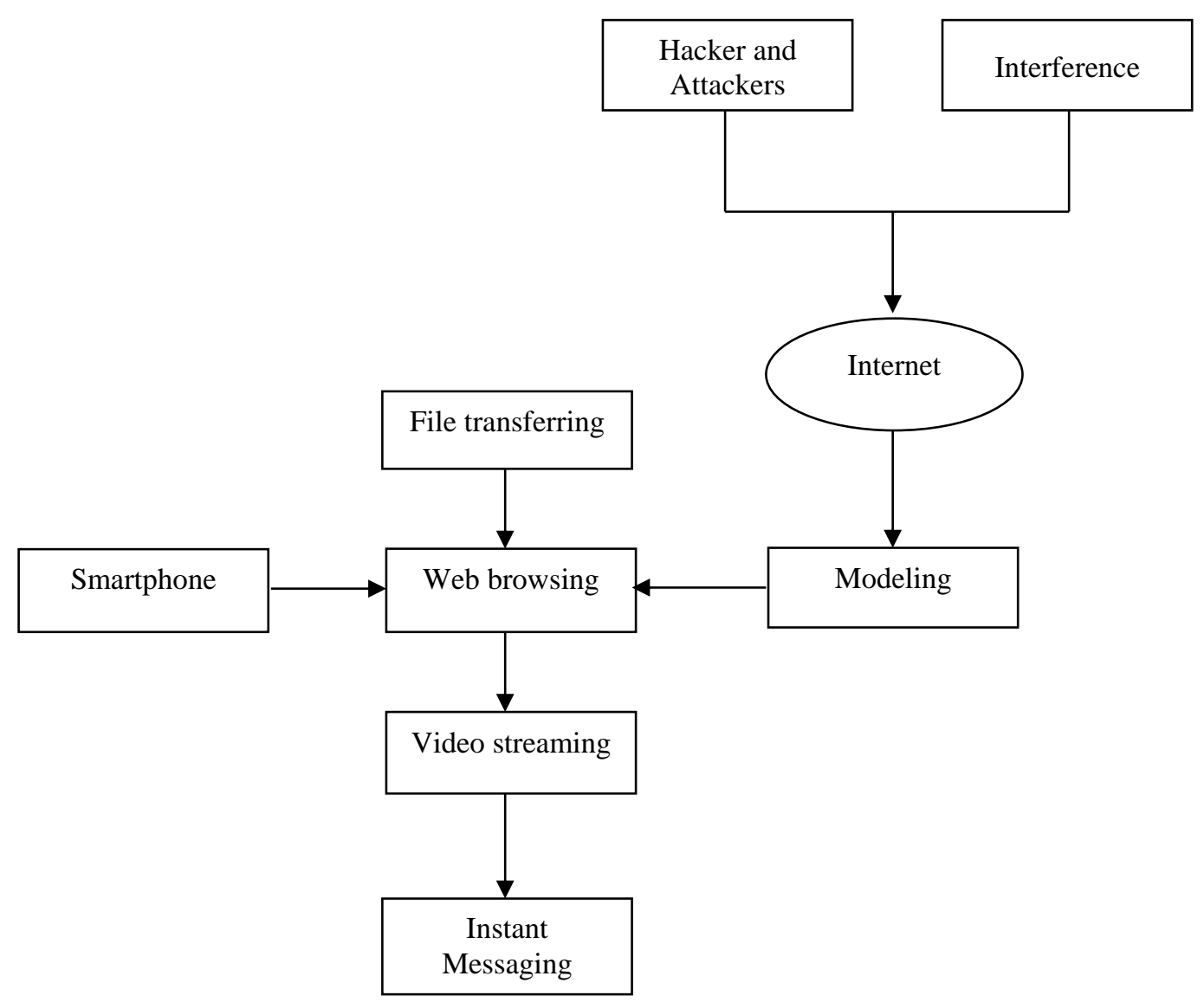

\section{RESULTS AND DISCUSSION}

Control state device of hardware sector includes the condition change dissimilar by the power economy method in utilising an 802.11 WNI have three default working mode namely TRANSMIT, RECEIVE and inactive. The 802.11 PSM introduce a new operating method called SLEEP. Influence model that define variables with burst dimension/extent and information quickness.

\section{CONCLUSION}

To develop a test suite that has the common energy-demanding function the GI run on the resource code of each test case to make a new version of the original test container. Inside the next step, the framework compares the energy consumption of the modified test case either through an actual achievement or our power representation. Indeed, a fitter solution consumes fewer influences.

\section{REFERENCES}

[1] Qian F., et al., "Profiling resource usage for mobile applications: A cross-layer approach in Proceedings," Monists Bethesda: MD, USA, 2011.

[2] Friedman R., et al., "On power and throughput tradeoffs of Wi-Fi and Bluetooth in smartphones in Proceedings," INFOCOM, Shanghai, China, 2011.

[3] Hemavathy E., "Design and Development of Simple Guiding Blood Pressure Measurement (SGBPM) Mobile Application," Indian Journal of Science and Technology, vol. 7, pp. 6, 2014.

[4] Kannan G., et al., "Reactive power optimisation using firefly algorithm," In Power Electronics and Renewable Energy Systems, Springer India, pp. 83-90, 2015.

[5] Cuervo, et al., "MAUI: Making smartphones last longer with code offload in Proceedings," Monists, San Francisco, CA, USA, 2012. 